\title{
Molecular Docking and Evaluation of Antileishmania Activity of a Ruthenium Complex with Epiisopiloturine and Nitric Oxide
}

\author{
Joabe Lima Araújo 1,2,3*, Ruan Sousa Bastos ${ }^{2,3,4}$, Gardênia Taveira Santos ${ }^{5}$, \\ Michel Muálem de Moraes Alves', Kayo Alves Figueiredo7 ${ }^{7}$ Lucas Aires de Sousa ${ }^{8}$, \\ Ionara Nayana Gomes Passos ${ }^{2}$, Fernando Aécio de Amorim Carvalho9, \\ Francisco das Chagas Alves Lima ${ }^{10}$, Jefferson Almeida Rocha ${ }^{2,3}$
}

\author{
${ }^{1}$ Postgraduate Program in Nanoscience and Nanobiotechnology, Department of Genetics and Morphology, University of Brasília, \\ Brasília, DF, Brazil \\ ${ }^{2}$ Research Group in Natural Sciences and Biotechnology, Department of Natural Sciences/Chemistry, Federal University of \\ Maranhão, Grajaú, MA, Brazil \\ ${ }^{3}$ Research Group in Medicinal Chemistry and Biotechnology, QUIMEBIO, Federal University of Maranhão, São Bernardo, \\ MA, Brazil \\ ${ }^{4}$ Postgraduate Program in Medicinal Chemistry and Molecular Modeling, Federal University of Pará, Belém, PA, Brazil \\ ${ }^{5}$ Department of Nursing, State University of Maranhão, Colinas, MA, Brazil \\ ${ }^{6}$ Department of Veterinary Morphophysiology, Federal University of Piauí, Teresina, PI, Brazil \\ ${ }^{7}$ Department of Health, Federal Institute of Education, Science and Technology of Piauí, Teresina, PI, Brazil \\ ${ }^{8}$ Postgraduate Program in Materials Science, Center for Social Sciences, Health and Technology, Federal University of Maranhão, \\ Imperatriz, MA, Brazil \\ ${ }^{9}$ Department of Biochemistry and Pharmacology, Federal University of Piauí, Teresina, PI, Brazil \\ ${ }^{10}$ Department of Chemistry, Quantum Computational Chemistry Laboratory, Federal University of Piauí, Teresina, PI, Brazil \\ Email: ${ }^{*}$ joabearaujobiotec@gmail.com
}

How to cite this paper: Araújo, J.L., Bastos, R.S., Santos, G.T., de Moraes Alves, M.M., Figueiredo, K.A., de Sousa, L.A., Passos, I.N.G., de Amorim Carvalho, F.A., das Chagas Alves Lima, F. and Rocha, J.A. (2020) Molecular Docking and Evaluation of Antileishmania Activity of a Ruthenium Complex with Epiisopiloturine and Nitric Oxide. Journal of Biosciences and Medicines, 8, 42-53.

https://doi.org/10.4236/jbm.2020.85005

Received: March 7, 2020

Accepted: April 27, 2020

Published: April 30, 2020

\begin{abstract}
Leishmaniasis is an infectious disease that affects both animals and humans, caused by flagellated parasites belonging to the genus Leishmania. The disease is estimated to reach about 700,000 to 1 million people, causing the deaths of 20 to 30,000 individuals annually. Thus, the present study aims to perform molecular docking tests and evaluation of antileishmania activity in vitro of a ruthenium complex with epiisopiloturine and nitric oxide. AutoDockTools-1.5.6 software was used to perform molecular docking tests. Molecular targets were considered rigid, and Epiruno ${ }_{2}$ considered flexible. The genetic algorithm Lamarckian (AGL) with global search and pseudo-Solis and Wets with local search were the methods adopted in the docking. The most promising results of molecular interaction were achieved in the targets Pteridine reductase and UDP-glucose Pyrophosphorylase with rates of $-10.68 \mathrm{Kcal} \cdot \mathrm{mol}^{-1}$ and -10.51 $\mathrm{Kcal} \cdot \mathrm{mol}^{-1}$, respectively. This demonstrates that Epiruno ${ }_{2}$ has molecular affinity with the targets of $L$. major. In vitro assays prove the antileishmania activity of
\end{abstract}


Copyright $\odot 2020$ by author(s) and Scientific Research Publishing Inc. This work is licensed under the Creative Commons Attribution International License (CC BY 4.0). http://creativecommons.org/licenses/by/4.0/ the complex in the face of promastigote forms with inhibition of growth, concluding through this study that the Epiruno ${ }_{2}$ complex has antileishmania activity.

\section{Keywords}

Molecular Docking Simulation, Neglected Diseases, Leishmania major

\section{Introduction}

Leishmaniasis is a disease that affects more than 98 countries worldwide, with about 700,000 to 1 million new cases reported annually, and an annual rate of 20 to 30,000 deaths [1]. There are several ways for the disease to manifest clinically, and may present as cutaneous, mucocutaneous and visceral. Infection with Leishmania major ( $L$. major) species has a chronic evolution that affects the structures of the nasopharyngeal epidermis and cartilage, either localized or diffuse [2]. The parasitic cycle results from the abundance of carbohydrates on the surface of Leishmania, which includes lipophosphoglycans, glycosylphosphatidylinositol lipid-anchored proteins and proteophosphoglycans [3]. These glycoproteins are part of the promastigote infectious glycocalyx, which is the most important process in host infectivity [4] and phlebotomine interaction [5].

After diagnosis, the patient undergoes treatment that depending on the infecting strain will be treated with some of the drugs available on the pharmaceutical market, they are: pentavalent antimonial; AmBisomew; liposomal; amphotericin B; miltefosine and diamidines, among others. All of these drugs are potentially toxic and have reduced efficacy in addition to adverse side effects. That in many cases, the patient chooses not to undergo treatment so that he does not suffer from side effects caused by drugs [6] [7].

Besides this problem, the pharmaceutical industries neglect investments in the search for new pharmacological agents that present high inhibition rates with new mechanisms of action and low toxicity. This lack of interest is related to market demand, as it is a neglected disease, that is, it affects only underdeveloped and developing countries, the sector has high risks of not making profits on their investments, because the population would not be able to afford it. With the costs of treatment, even the state would not be able to finance the services offered by the industries [8].

Thus, there is a clear need to search for new compounds with pharmacological potential and low toxicity by alternative methods that bring reliability in their results, speed and cost benefit. Thus, computational quantum chemistry presents itself as a promising alternative, using several computational tools that predict molecular properties related to a pharmacological potential. Using the laws of quantum chemistry and various programming techniques that are capable of predicting energy state, molecular structures, vibrational frequencies of atomic and molecular systems and molecular interaction between two molecules devel-oping virtual models saving time and materials that would be wasted on experiments in the field laboratory [9] [10]. 
In this sense, ruthenium $(\mathrm{Ru})$ complexes have become attractive in pharmacological studies because they have low toxicity and are an excellent conductor of energy when dealing with a transition metal, where it plays an important role in the bioactive process of a compound in reaction with a target disease, having little energy loss in its path [11] [12]. The Ru complex with epiisopiloturin and nitric oxide $\left(\right.$ Epiruno $\left._{2}\right)$ was synthesized by Rocha (2018) in anti-schistosoma mansoni studies, where the Epiruno ${ }_{2}$ complex showed schistosomicidal activity in sílico and ex vivo studies. There was a 10-fold increase in the biological activity of Epiisopiloturin (EPI) when coupled with the Ru complex against Schistosoma parasites, eliminating $60 \%$ of male worms at a concentration of $50 \mu \mathrm{M}$ within 72 hours, showing antiparasitic activity [13].

Associated with the antiparasitic schistosomicidal effect presented by the Epiruno $_{2}$ complex in studies by Rocha (2018), we assume that the complex has antileishmania activity. Thus, the present study aims to perform molecular docking tests and evaluation of antileishmania activity in vitro of a ruthenium complex with epiisopiloturine and nitric oxide.

\section{Materials and Methods}

\subsection{Molecular Docking}

The 3D molecules of $L$. major targets were extracted from the PDB (Protein data Bank) database with codes 5g20 (Glycyl Peptide N-tetradecanoyltransferase); 5nzg (UDP-glucose Pyrophosphorylase); 5c7p (Nucleoside diphosphate kinase); 1e7w (Pteridine reductase); and lezr (Nucleoside hydrolase) [14] prepared for docking by removing mutant chains and all water molecules, ions and other groups using Chimera v.13.1 software [15] [16].

The three-dimensional molecular structure of the Epiruno ${ }_{2}$ complex was designed using GaussView 5.0 software [17] and optimized by DFT (Density Functional Theory) calculation using the B3lyp functional and the $6-311^{++} \mathrm{G}(\mathrm{d}, \mathrm{p})$ available in Gaussian 09 W software [18] [19].

The molecular docking process followed the protocol developed by Rocha and collaborators, with some modifications [20]. All molecular docking procedures were performed by AutoDockTools-1.5.6 software [21]. L. major targets and the Epiruno $_{2}$ complex were prepared for docking simulations, where targets were considered rigid and Epiruno ${ }_{2}$ was considered flexible. Partial charges were calculated after the addition of all hydrogens. The nonpolar hydrogen atoms of the protein and binder were subsequently fused. A $60 \times 60 \times 60$ point cubic box with a spacing of $0.375 \AA$ between grid points was generated for the simulations. The molecular affinity grid centers were defined from the coordi-nates of the atoms of their respective active sites Asn376, Lys380, Gly91, Asn109 and Asp15, respectively.

The Lamarckian global search (LGA) genetic algorithm [22] and the pseudo-Solis and Wets [23] local search (LS) methods were applied in the search for molecular docking. The Epiruno ${ }_{2}$ complex was subjected to 100 independent 
runs of molecular coupling simulations [24]. The remaining parameters were set to default values.

Molecular docking analysis focused on the results that presented lower fitting conformation with lower $G_{b i n d}^{a}$ energy, in addition to the interactions by hy-

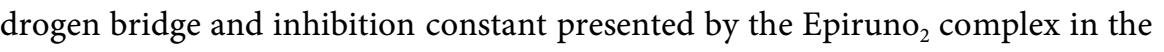
of the molecular targets of $L$. major.

\subsection{In Vitro Trials on Promastigote forms MHOM/IL/80/Friedlin of L. major}

For in vitro assays, the method adopted by Carneiro and collaborators was used, with some modifications [25]. The MHOM/IL/80/Friedlin promastigotes of $L$. major were donated by the Laboratory of Antileishmania Activity, located at the Research Core in Medicinal Plants of the Federal University of Piauí-UFPI and cultivated in Schneider media (Sigma, USA), supplemented with $10 \%$ bovine fetal serum (BFS) (Sigma, USA) and penicillin-streptomycin 10,000 IU/10mg (Sigma, USA) at $26^{\circ} \mathrm{C}$ in a greenhouse of biological oxygen demand (BOD).

L. major promastigote forms $\mathrm{MHOM} / \mathrm{IL} / 80 /$ Friedlin in log phase were seeded $1 \times 10^{6}$ parasites per well in a 96-well cell culture microplate containing supplemented Schneider medium and Epiruno ${ }_{2}$ at serial concentrations of 800 to 6.25 $\mu \mathrm{g} / \mathrm{mL}$, respectively. Then the plates were incubated in a BOD greenhouse at $26^{\circ} \mathrm{C}$. After $48 \mathrm{~h}$ resazurine $(1 \mathrm{mM})$ was added and the plate was re-infiltrated in the BOD incubator for another $6 \mathrm{~h}$. Then the spectrophotometer reading was performed to obtain the optical density at $550 \mathrm{~nm}$. Negative control was performed with Schneider medium at $0.2 \%$ DMSO and considered as $100 \%$ viability of the parasites. The amphotericin B (Amp-B) at a concentration of $2 \mu \mathrm{g} / \mathrm{mL}$ was used as a positive control to validate the experiment.

\section{Results and Discussion}

\subsection{Molecular Docking}

The evaluation criteria were defined by the results that showed lower cluster conformation with lower $G_{b i n d}^{a}$ energy, besides the hydrogen bridge interac-

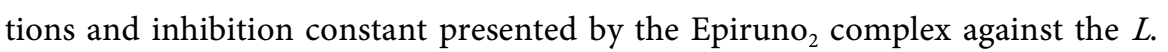
major molecular targets.

The molecular docking between the Epiruno ${ }_{2}$ complex and the $1 \mathrm{e} 7 \mathrm{w}$ protein obtained the lowest $G_{b i n d}^{a}$ energy among all molecular couplings performed in this study, obtaining an energy of $-10.68 \mathrm{Kcal} \cdot \mathrm{mol}^{-1}$ and an inhibition constant of $14.8 \mathrm{nM}$ (Table 1). This low $G_{b i n d}^{a}$ energy indicates high molecular affinity of the complex with the target protein [26]. Thus, inhibiting its action would be to interrupt the disease development process, since the $1 \mathrm{e} 7 \mathrm{w}$ enzyme has a function of reducing conjugated and unconjugated pterins, one example is biopterin and dihydrobiopterin (DHB), followed by 5, 6, 7, 8-tetrahydrobiopterin (THB) or DHF folate. It is the only protein known to reduce biopterin in Leishmania, proving to be essential for in vivo growth through genetic knockout studies [27]. 
Table 1. Molecular affinity parameters of the Epiruno ${ }_{2}$ complex with L. major targets.

\begin{tabular}{cccccc}
\hline $\begin{array}{c}\text { Complex } \\
\text { (Protein-ligand })\end{array}$ & $\begin{array}{c}\Delta G_{\text {bind }}^{a} \\
\left(\mathrm{kcal} \cdot \mathrm{mol}^{-1}\right)\end{array}$ & Kib $(\mu \mathrm{M})$ & $\begin{array}{c}\text { Number of independent } \\
\text { docking runs }\end{array}$ & $\begin{array}{c}\text { Number of conformations } \\
\text { in the first ranked cluster }\end{array}$ & $\begin{array}{c}\text { Amino acids that interact through } \\
\text { hydrogen bondsc }\end{array}$ \\
\hline Epiruno $_{2} / \mathrm{le} 7 \mathrm{w}$ & -10.68 & $14.8 \mathrm{nM}$ & 100 & 7 & Asp232, Lys198, Ser111, Ser227 \\
Epiruno $_{2} / 5 \mathrm{nzg}$ & -10.51 & $19.74 \mathrm{nM}$ & 100 & 81 & Asp221, Gly220, Lys95 \\
Epiruno $_{2} / 5 \mathrm{~g} 20$ & -9.65 & $83.81 \mathrm{nM}$ & 100 & 43 & Arg104, Asn114, Ser98 \\
Epiruno $_{2} / 5 \mathrm{c7p}$ & -8.22 & $935.7 \mathrm{nM}$ & 100 & 4 & Pro11, gln40 \\
\hline
\end{tabular}

Note: Epiruno $_{2}$-ruthenium complex with epiisopiloturine and nitric oxide; 1e7w-Pteridine reductase; 5nzg-UDP-glucose Pyrophosphorylase; 5g20-Glycyl Peptide N-tetradecanoyltransferase; 5c7p-Nucleoside diphosphate kinase; and lezr-Nucleoside hydrolase. (Araújo et al., 2020).

The most intense interactions between the target protein and the Epiruno ${ }_{2}$ complex occur between the residues Asp232, Lys198, Ser111 and Ser227, places where the highest intermolecular forces act (Figure 1).

The Epiruno ${ }_{2}$ complex also showed excellent molecular affinity results with the target protein $5 \mathrm{nzg}$ of $L$. major, obtaining a $G_{\text {bind }}^{a}$ energy of $-10.51 \mathrm{Kcal} \cdot \mathrm{mol}^{-1}$ (Table 1) and formation of three hydrogen bridges located on amino acids Asp211, Gly220 and Lys95, where the most intense interactions between the complex and the target protein occur (Figure 1). This may be related to UGP (UDP_glucose pyrophosphorylase) catalyzing the synthesis of activated form glucose, UDP-Glc, uridine triphosphate (UTP) and glu-cose-1-phosphate (Glc-1p). Because the UDP-Glc reaction is critical in the production of carbohydrates such as cell surface glycans and other pathogen processes becoming an attractive target in interaction and molecular inhibition studies [28] [29] [30]. The resulting inhibition constant was $19.74 \mathrm{nM}$, presenting antileishmania inhibitory activity of the Epi$\mathrm{runo}_{2}$ complex against target protein 5nzg (Table 1).

This result indicates that the Epiruno ${ }_{2}$ complex has antileishmania inhibitory activity, since docking studies analyze the inhibitory action of coupled compounds at the active site of the target protein [26] even if there is a difference between in sílico and in vitro experiments, the results tend to differ, where in sílico studies by molecular docking pre-dict quickly and reliably if a compound has biological activity and experimental labora-tory studies validate their analyzes, complementing each other, providing technical via-bility in the results presented [31] [32].

The $5 \mathrm{~g} 20$ protein also showed molecular affinity with the Epiruno ${ }_{2}$ complex obtaining attractive $G_{\text {bind }}^{a}$ energy in docking molecular affinity studies with -9.65 Kcal. $\mathrm{mol}^{-1}$ and an inhibition constant of $83.81 \mathrm{nM}$ [26] (Table 1). This molecular interaction did not result in hydrogen bridges, unlike previous interactions between the Epiruno ${ }_{2}$ complex with the $1 \mathrm{e} 7 \mathrm{w}$ and 5nzg proteins that had 4 and 3 hydrogen bridges, respectively, however, the interactions in the Val374, Leu227 and His219 residues make intense interactions in the active site borders of the protein, in particular the interactions Val374 with $\mathrm{O} 1$ and Leu227 with $\mathrm{O} 2$ and 

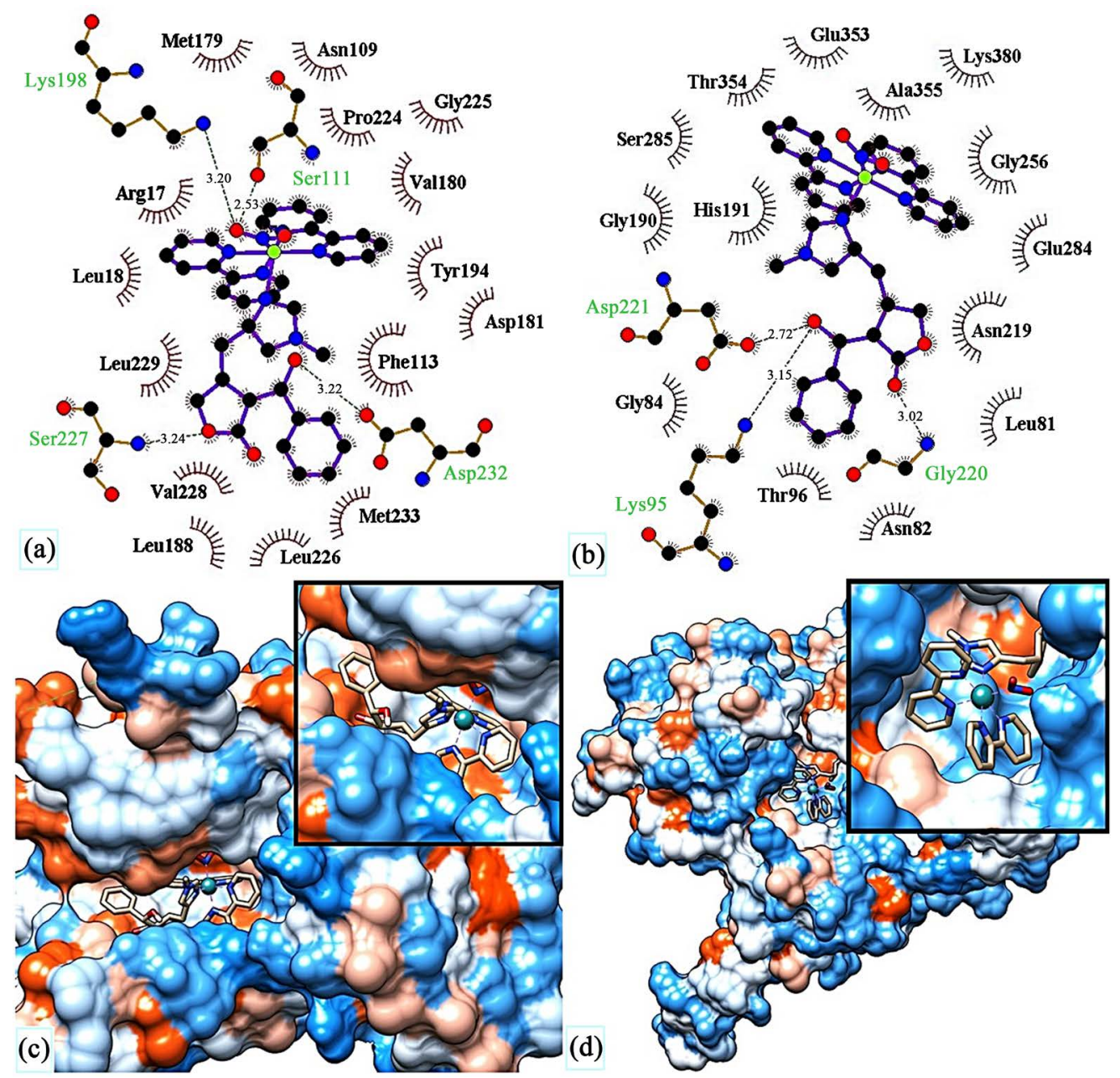

Figure 1. Molecular docking between Epiruno ${ }_{2}$ complex and $1 \mathrm{e} 7 \mathrm{w}$ and $5 \mathrm{nzg}$ target proteins. (a) Docking at target protein active site $1 \mathrm{e} 7 \mathrm{w}$; (b) molecular interaction between Epiruno $_{2}$ and target protein 1e7w; (c) Docking at 5nzg target protein active site; (d) molecular interaction between Epiruno $_{2}$ and 5 nzg target protein.

both residues with C8 (Figure 2). These interactions at the edges of the active site make the Epiruno ${ }_{2}$ complex have a very promising high inhibitory action, and the tertiary structure is part of recognition elements that facilitate the molecular interactions between protein and ligand, in this case the Epiruno ${ }_{2}$ complex [33] [34].

Molecular docking between the $5 \mathrm{c} 7 \mathrm{p}$ protein and the Epiruno $_{2}$ complex formed three hydrogen bridges at amino acids Arg104, Asn114 and Ser98 (Figure 2) and showed $G_{\text {bind }}^{a}$ energy of $-8.22 \mathrm{Kcal} \cdot \mathrm{mol}^{-1}$ and an inhibition constant of $935.7 \mathrm{nM}$ (Table 1). These results are promising against this indispensable protein for the maintenance of intracellular nucleoside triphosphate (NTP) levels [35]. They carry the $\gamma$-phosphoryl group from an NTP to a nucleoside diphosphate (NDP) through a functional scheme called ping-pong involving the covalent intermediate phosphohistidine. Eukaryotic NDKs are composed of 15 to $18 \mathrm{KDA}$ subunits with similarities in their general structures and a conserved active site [36] [37]. 

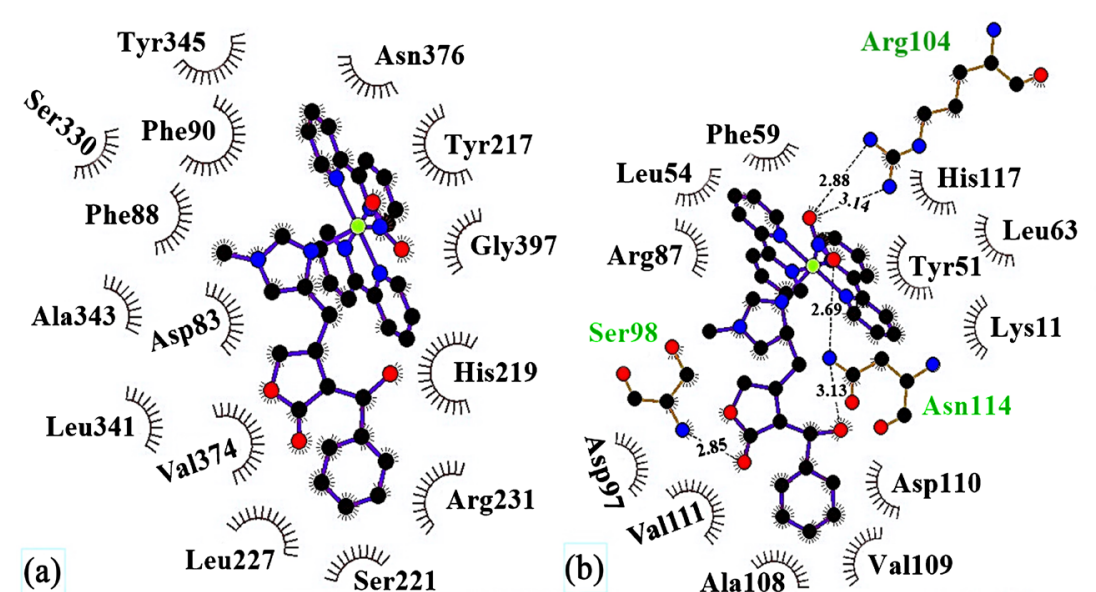

(b)
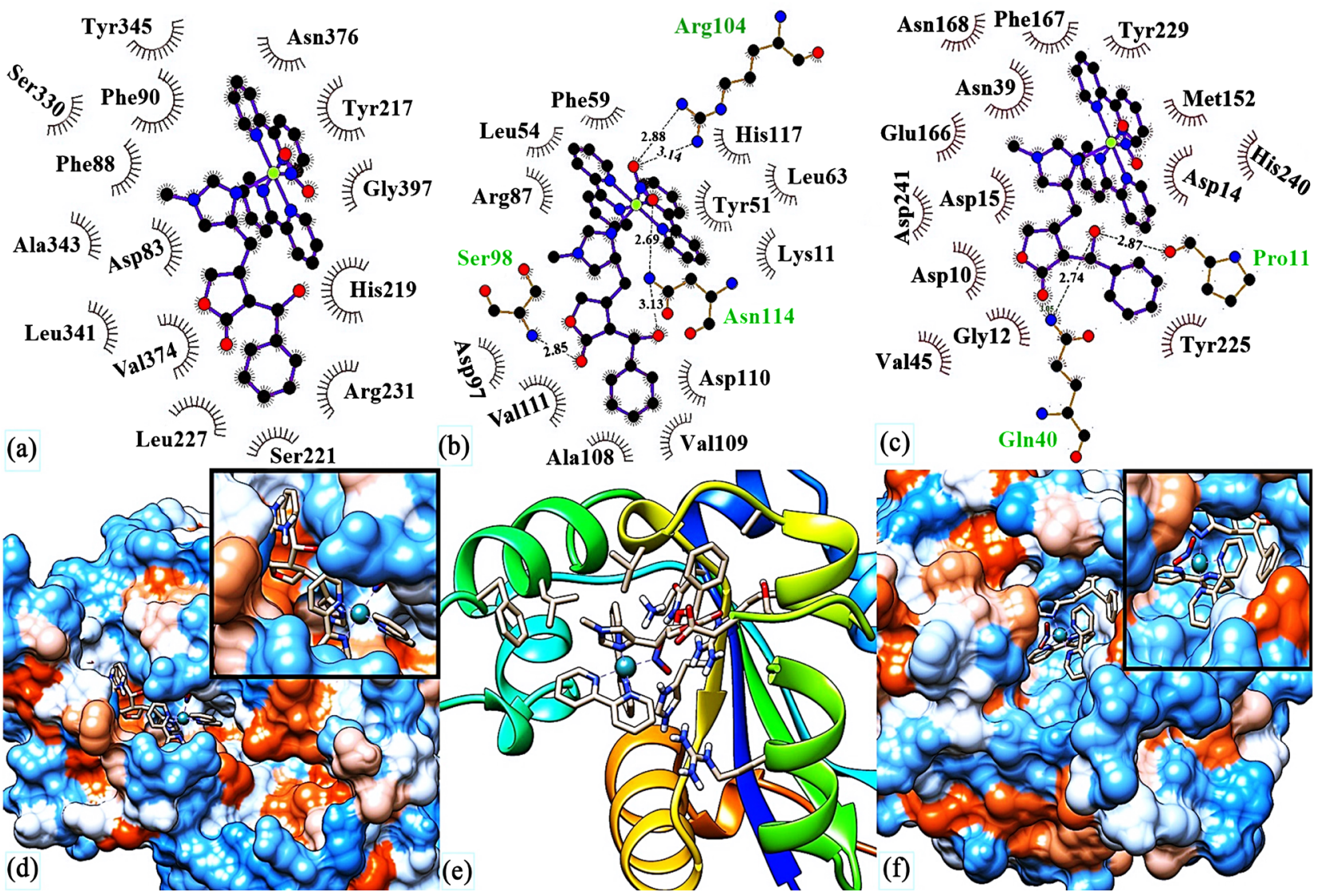

Figure 2. Molecular docking between the Epiruno $_{2}$ complex and the $5 \mathrm{~g} 20,5 \mathrm{c} 7 \mathrm{p}$ and 1ezr proteins. (a) Docking at active site of protein 5g20; (b) molecular interaction between 5g20 protein and Epiruno ${ }_{2}$ complex; (c) molecular interaction between 5c7p protein and

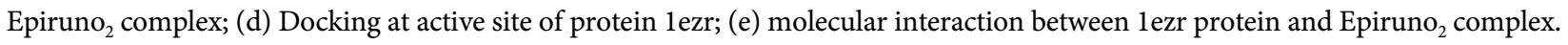

The lezr protein can be identified in free extracts of Leishmania cells, is also present in several parasitic protozoa. It is a protein useful in parasitic infections, acting as a catalyst for the hydrolysis of both purine and pyrimidine nucleosides [38] [39], where its inhibition is fundamental for the treatment of $L$. major. In this sense, the Epiruno ${ }_{2}$ complex presented interesting interaction and molecular affinity results, obtaining a $G_{\text {bind }}^{a}$ energy of $-8.19 \mathrm{Kcal}^{\mathrm{mol}}{ }^{-1}$ and an inhibition constant of $996.06 \mathrm{nM}$ [26] (Table 1). The most intense interactions between the complex and the protein occur at residues Pro11 and Gln40, the two hydrogen bonds formed (Figure 2).

\subsection{In Vitro Trials on Promastigote Forms MHOM/IL/80/Friedlin of $L$. major}

In these trials we evaluated the leishmanicidal effects of the Epiruno ${ }_{2}$ complex against $L$. major promastigote $\mathrm{MHOM} / \mathrm{IL} / 80 /$ Friedlin parasites. The Epiruno ${ }_{2}$ complex showed $50.53 \%$ inhibition of promastigote growth at a concentration of $800 \mu \mathrm{g} / \mathrm{mL}$ (Figure 3), a significant reduction by analyzing the half maximal inhibitory concentration (CI-50) (Table 2) showing antileishmania activity, confirming the results presented in sílico tests by molecular docking. However, these 
values are not considered clinically relevant, according to Santos et al. [40], which defines in their studies that only IC-50 lower than $500 \mu \mathrm{g} / \mathrm{mL}$ can be considered therapeutically relevant.

It is observed that the results presented in molecular docking analyzes were more promising than the results presented in vitro assays. This may be related to the topological polar surface area (TPSA), which uses functional groups obtained from a structural database, avoiding calculations of the ligand's three-dimensional (3D) structures, in this case the Epiruno ${ }_{2}$ complex or the confirmation of which conformation. Since this biological method is relevant, this method is used in $2 \mathrm{D}$ structures for 14 sets of diverse pharmacological activity data. This methodology is promising for classic $2 \mathrm{D}$ descriptors such as calculated $\log \mathrm{P}(\mathrm{C} \log \mathrm{P})$ and calculated molar refractivity (CMR) in the 2D-QSAR literature [41].

The discovery of new antileishmania chemical compounds has long been realized from the isolation of plant extracts. There are already several extracts and compounds that have proven antileishmania activity on promastigote and amastigote forms of through in vitro assays [42] [43] [44]. Despite several microbiological studies, several analyzes of new compounds extracted from natural and synthetic resources are still needed, as the search for new pharmacological potential leishmanicide has been important, since the drugs in the pharmacological market have high toxicity and reduced efficacy [6] [45].

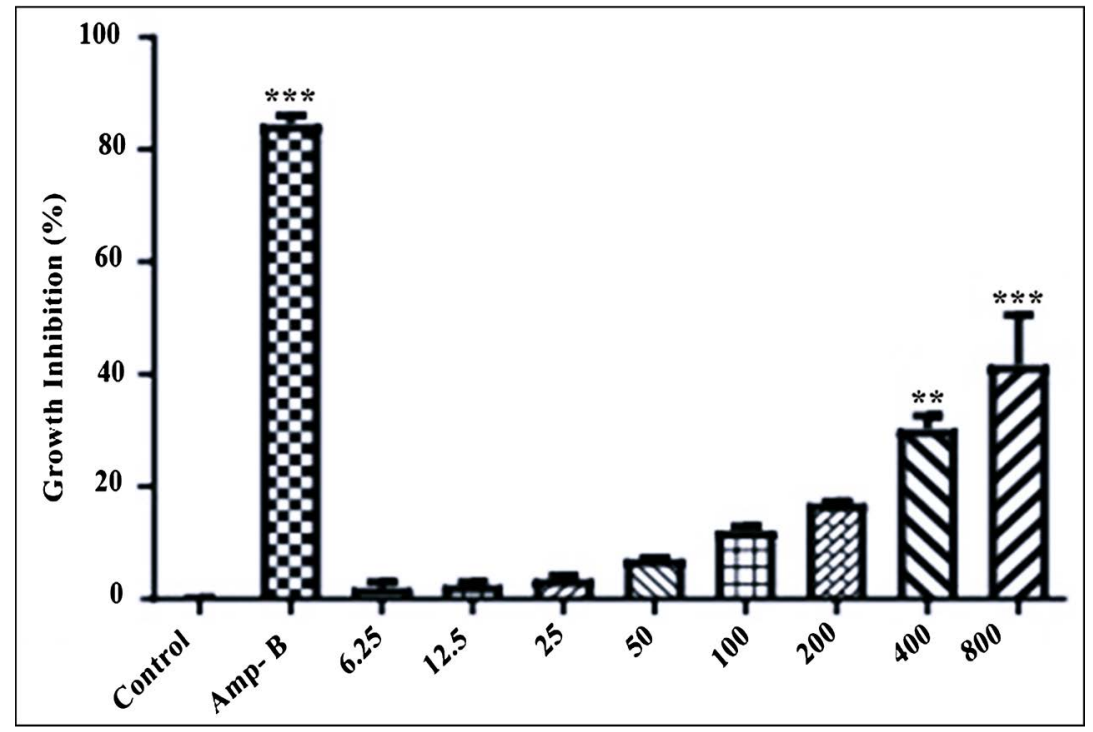

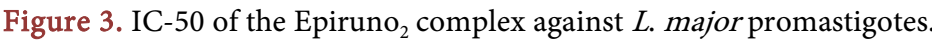

Table 2. IC-50 values of $L$. major promastigotes in the presence of the Epiruno ${ }_{2}$ complex.

Epiruno $_{2}$ complex

$\begin{array}{lc}\text { L. major } & \text { MHOM/IL/80/Friedlin } \\ \text { IC-50 } & 800 \mu \mathrm{g} / \mathrm{mL}\end{array}$

Note: IC-50 - half maximal inhibitory concentration (Araújo et al., 2020). 


\section{Conclusions}

The Epiruno ${ }_{2}$ complex presented antileishamania activity both in sillico studies by molecular docking and in vitro study. Its best molecular affinity parameter presented in docking studies was for target proteins $1 \mathrm{e} 7 \mathrm{w}$ and $5 \mathrm{nzg}$ with $G_{\text {bind }}^{a}$ energies $-10.68 \mathrm{Kcal} \cdot \mathrm{mol}^{-1}$ and $-10.51 \mathrm{Kcal} \cdot \mathrm{mol}^{-1}$, respectively. In addition to these two targets, it was found that the complex has molecular affinity for the other molecular targets of L. major analyzed in this study.

In vitro assays proved the antileishmania activity of the complex against $L$. major promastigotes MHOM/IL/80/Friedlin with significant growth inhibitions. However, the values are not considered clinically relevant, concluding from in sílico and in vitro studies that the Epiruno $_{2}$ complex has antiparasitic activity that can be tested on other Leishmania targets such as $L$. amazonensis and $L$. Chagasi and also in other pathogens.

\section{Acknowledgements}

To the Department of Natural Sciences/Chemistry at the Federal University of Maranhão-UFMA, campus of Grajaú, MA and to the members of the Laboratory of Antileishmania Activity, located at the Research Center for Medicinal Plants at the Federal University of Piauí-UFPI.

\section{Conflicts of Interest}

The authors declare no conflicts of interest regarding the publication of this paper.

\section{References}

[1] Colina-vegas, L., et al. (2019) Antiparasitic Activity and Ultrastructural Alterations Provoked by Organoruthenium Complexes against Leishmania amazonensis. New Journal of Chemistry, 43, 1431-1439. https://doi.org/10.1039/C8NJ04657C

[2] Scott, P. and Novais, F.O. (2016) Cutaneous Leishmaniasis: Immune Responses in Protection and Pathogenesis. Nature Reviews Immunology, 16, 581-592. https://doi.org/10.1038/nri.2016.72

[3] Ilg, T. (2000) Proteophosphoglycans of Leishmania Parasitol. Today, 16, 489-497. https://doi.org/10.1016/S0169-4758(00)01791-9

[4] Descoteaux, A. and Turco, S.J. (1999) Glycoconjugates in Leishmania Infectivity. Biochimica et Biophysica Acta, 1455, 341-352. https://doi.org/10.1016/S0925-4439(99)00065-4

[5] Sacks, D.L. (2001) Leishmania-Sand Fly Interactions Controlling Species-Specific Vector Competence: Microreview. Cellular Microbiology, 3, 189-196. https://doi.org/10.1046/j.1462-5822.2001.00115.x

[6] Croft, S.L. and Coombs, G.H. (2003) Leishmaniasis-Current Chemotherapy and Recent Advances in the Search for Novel Drugs. Trends in Parasitology, 19, 502-508. https://doi.org/10.1016/j.pt.2003.09.008

[7] Zuben, A.P.B., et al. (2014) The First Canine Visceral Leishmaniasis Outbreak in Campinas, State of São Paulo Southeastern Brazil. Revista da Sociedade Brasileira de Medicina Tropical, 47, 385-388. https://doi.org/10.1590/0037-8682-0126-2013

[8] Ahmed, K., et al. (2016) A Second WNT for Old Drugs: Drug Repositioning against WNT-Dependent Cancers. Cancers, 8, 66. https://doi.org/10.3390/cancers8070066 
[9] Rappoport, D. and Furche, F. (2010) Property-Optimized Gaussian Basis Sets for Molecular Response Calculations. The Journal of Chemical Physics, 133, Article ID: 134105. https://doi.org/10.1063/1.3484283

[10] Araújo, J.L., et al. (2019) Estudo in sílico da atividade biológica por docagem molecular da desloratadina contra esquistossomose. Revista Eletrônica Acervo Saúde, No. 28, e993. https://doi.org/10.25248/reas.e993.2019

[11] Batchelor, T.T., et al. (2007) AZD2171, a Pan-VEGF Receptor Tyrosine Kinase Inhibitor, Normalizes Tumor Vasculature and Alleviates Edema in Glioblastoma Patients. Cancer Cell, 11, 83-95. https://doi.org/10.1016/j.ccr.2006.11.021

[12] Bruijnincx, P.C.A. and Sadler, P.J. (2008) New Trends for Metal Complexes with Anticancer Activity. Current Opinion in Chemical Biology, 12, 197-206.

https://doi.org/10.1016/j.cbpa.2007.11.013

[13] Rocha, J.A. (2018) Planejamento racional, síntese, caracterização e estudo in silico de complexos metálicos de rutênio e alcaloides de pilocarpus microphyllus contra a esquistossomose [tese]. Universidade Federal do Piauí, Teresina.

[14] Berman, H.M., et al. (2000) The Protein Data Bank. Nucleic Acids Research, 28, 235-242. https://doi.org/10.1093/nar/28.1.235

[15] Pettersen, E.F., et al. (2004) UCSF Chimera: A Visualization System for Exploratory Research and Analysis. Journal of Computational Chemistry, 25, 1605-1612. https://doi.org/10.1002/jcc.20084

[16] Araújo, J.L., et al. (2019) Evaluation by Molecular Docking of Inhibitors of the Enzyme Pteridine Reductase 1 from Leishmania. Revista Prevenção de Infecção e Saúde, 5, e9056. https://doi.org/10.26694/repis.v5i0.9056

[17] Frisch, A.E., et al. (2009) Gauss-View, Version 5.0.8. Gaussian, Wallingford.

[18] Kohn, W. and Sham, L.J. (1965) Self-Consistent Equations Including Exchange and Correlation Effects. Physical Review, 140, A1133. https://doi.org/10.1103/PhysRev.140.A1133

[19] Barone, V., et al. (2002) DFT Calculation of NMR JFF Spin-Spin Coupling Constants in Fluorinated Pyridines. Journal of Physical Chemistry A, 106, 5607-5612. https://doi.org/10.1021/jp020212d

[20] Rocha, J.A., et al. (2018) Computational Quantum Chemistry, Molecular Docking, and ADMET Predictions of Imidazole Alkaloids of Pilocarpus microphyllus with Schistosomicidal Properties. PLoS ONE, 13, e0198476. https://doi.org/10.1371/journal.pone.0198476

[21] Goodsell, D.S., et al. (1996) Automated Docking of Flexible Ligands: Applications of AutoDock. Journal of Molecular Recognition, 9, 1-5. https://doi.org/10.1002/(SICI)1099-1352(199601)9:1<1::AID-JMR241>3.0.CO;2-6

[22] Morris, G.M., et al. (1998) Automated Docking Using a Lamarckian Genetic Algorithm and an Empirical Binding Free Energy Function. Journal of Computational Chemistry, 19, 1639-1662.

https://doi.org/10.1002/(SICI)1096-987X(19981115)19:14<1639::AID-JCC10>3.0.C $\underline{\mathrm{O} ; 2-\mathrm{B}}$

[23] Solis, F.J. and Wets, R.J.-B. (1981) Minimization by Random Search Techniques. Mathematics of Operations Research, 6, 19-30. https://doi.org/10.1287/moor.6.1.19

[24] Ramos, R.M., et al. (2012) Interaction of Wild Type, G68R and L125M Isoforms of the Arylamine-n-acetyltransferase from Mycobacterium tuberculosis with Isoniazid: A Computational Study on a New Possible Mechanism of Resistance. Journal of Molecular Modeling, 18, 4013-4024. https://doi.org/10.1007/s00894-012-1383-6 
[25] Carneiro, S.M.P., et al. (2012) The Cytotoxic and Antileishmanial Activity of Extracts and Fractions of Leaves and Fruits of Aaadirachta indica (A juss.). Biological Research, 45, 111-116. https://doi.org/10.4067/S0716-97602012000200002

[26] Bora-tatar, G., et al. (2009) Molecular Modifications on Carboxylic Acid Derivatives as Potent Histone Deacetylase Inhibitors: Activity and Docking Studies. Bioorganic \& Medicinal Chemistry, 17, 5219-5228. https://doi.org/10.1016/j.bmc.2009.05.042

[27] Gourley, D.G., et al. (2001) Pteridine Reductase Mechanism Correlates Pterin Metabolism with Drug Resistance in Trypanosomatid Parasites. Nature Structural Biology, 8, 521-525. https://doi.org/10.1038/88584

[28] Führing, J., et al. (2012) Octamerization Is Essential for Enzymatic Function of Human UDP-Glucose Pyrophosphorylase. Glycobiology, 23, 426-437.

https://doi.org/10.1093/glycob/cws217

[29] Cramer, J.T., et al. (2018) Decoding Allosteric Networks in Biocatalysts: Rational Approach to Therapies and Biotechnologies. ACS Catalysis, 8, 2683-2692. https://doi.org/10.1021/acscatal.7b03714

[30] Lamerz, A.C., et al. (2006) Molecular Cloning of the Leishmania major UDP-Glucose Pyrophosphorylase, Functional Characterization, and Ligand Binding Analyses Using NMR Spectroscopy. The Journal of Biological Chemistry, 281, 16314-16322. https://doi.org/10.1074/jbc.M600076200

[31] Rao, S.N., et al. (2007) Validation Studies of the Site-Directed Docking Program LibDock.Journal of Chemical Information and Modeling, 47, 2159-2171. https://doi.org/10.1021/ci6004299

[32] Warren, G.L., et al. (2006) A Critical Assessment of Docking Programs and Scoring Functions. Journal of Medicinal Chemistry, 49, 5912-5931. https://doi.org/10.1021/jm050362n

[33] Goncalves, V., et al. (2017) Structure-Guided Optimization of Quinoline Inhibitors of Plasmodium N-myristoyltransferase. MedChemComm, 8, 191-197. https://doi.org/10.1039/C6MD00531D

[34] Chow, M., et al. (1987) Myristylation of Picornavirus Capsid Protein VP4 and Its Structural Significance. Nature, 327, 482-486. https://doi.org/10.1038/327482a0

[35] Araújo, J.L., et al. (2020) Molecular Docking of Rutenum Complex with Epiisopyloturin and Nitric Oxide against Nucleoside Diphosphate Kinase Protein Leishmania. Research, Society and Development, 9, e59922121. https://doi.org/10.33448/rsd-v9i2.2121

[36] Lascu, I. and Gonin, P. (2000) The Catalytic Mechanism of Nucleoside Diphosphate Kinases. Journal of Bioenergetics and Biomembranes, 32, 237-246. https://doi.org/10.1023/A:1005532912212

[37] Souza, T.A., et al. (2011) Molecular Adaptability of Nucleoside Diphosphate Kinase b from Trypanosomatid Parasites: Stability, Oligomerization and Structural Determinants of Nucleotide Binding. Molecular BioSystems, 7, 2189-2195. https://doi.org/10.1039/c0mb00307g

[38] Parkin, D.W., et al. (1997) Isozyme-Specific Transition State Inhibitors for the Trypanosomal Nucleoside Hydrolases. Biochemistry, 36, 3528-3534. https://doi.org/10.1021/bi962319v

[39] Parkin, D.W., et al. (1991) Nucleoside Hydrolase from Crithidia fasciculata. Metabolic Role, Purification, Specificity, and Kinetic Mechanism. The Journal of Biological Chemistry, 266, 20658-20665.

[40] Santos, K.K.A., et al. (2012) Trypanocide, Cytotoxic, and Antifungal Activities of Momordica charantia. Pharmaceutical Biology, 50, 162-166. https://doi.org/10.3109/13880209.2011.581672 
[41] Prasanna, S. and Doerksen, R.J. (2009) Topological Polar Surface Area: A Useful Descriptor in 2D-QSAR. Current Medicinal Chemistry, 16, 21-41. https://doi.org/10.2174/092986709787002817

[42] Camacho, M.D.R., et al. (2001) Terpenoids from Guarea rhophalocarpa. Phytochemistry, 56, 203-210. https://doi.org/10.1016/S0031-9422(00)00310-1

[43] Boeck, P., et al. (2006) Synthesis of Chalcone Analogues with Increased Antileishmanial Activity. Bioorganic \& Medicinal Chemistry, 14, 1538-1545.

https://doi.org/10.1016/j.bmc.2005.10.005

[44] Royo, V.A., et al. (2003) Biological Activity Evaluation of Dibenzilbutirolactones Lignans Derivatives against Leishmania braziliensis. Revista Brasileira de Farmacognosia, 13, 18-21. https://doi.org/10.1590/S0102-695X2003000400007

[45] Araújo, J.L., et al. (2020) Predição computacional de alvos moleculares de um complexo metálico de rutênio com epiisopiloturina e óxido nítrico. Revista de Saúde, 11, e993. 